\title{
A STUDY OF OPINION OF HOUSEWIVES REGARDING MUSIC EDUCATION CURRICULUM IN SCHOOLS OF CHANDIGARH
}

JYOTI SHARMA

Ph.D Research Scholar, Panjab University, Chandigarh

ABSTRACT
Music is a treasured aspect of our culture with its large impacts of human life.
Music is considered as a therapy for good health and wellness. Music is a part of
education in India. India education system has changed over the time. A major
change in our education system came with the colonization of the country by the
Britishers. The need to reform and restructure our education system has been
felt many times. However, no concrete steps have yet been taken in this
direction.
In India, music education comes under the arts education with other disciplines
i.e. visual arts, theater and dance in the National Curriculum Framework - 2005.
It is indicated in the curriculum that music education system should be available
as compulsory subject up to Class X. It is suggested that learning should be
emphasized rather than teaching and the approach should be participatory,
interactive and experimental.
The present paper is a study on the opinion of housewives in Chandigarh whose
children are studying in schools whether music be introduced as a subject and
seek suggestion/recommendation and to develop the opportunities for students
to learn music and to enrich teaching learning experience at schools.
KEYworDS
Music Education, Curriculum

\section{INTRODUCTION}

Indian education system is one of the oldest education systems around the globe. It is unfortunate that while the education systems of other nations have undergone major changes with the changing times and technological advancement we are still stuck with the old and mundane system. Neither has our system seen any major change in the curriculum nor has there been any significant change in the way the education is imparted.

Music education is a field of study associated with the teaching and learning of music. It touches on all learning domains, including the psychomotor domain (the development of skills), the cognitive domain (the acquisition of knowledge), and, in particular and significant ways, the affective domain (the learner's willingness to receive, internalize, and share what is learned), including music appreciation and sensitivity. Music training from preschool through postsecondary education is common in most nations because involvement with music is considered a fundamental component of human culture and behavior. Cultures from around the world have different approaches to music education, largely due to the varying histories and politics. Studies show that teaching music from other cultures can help students perceive unfamiliar sounds more comfortably, and they also show that musical preference is related to the 
language spoken by the listener and the other sounds they are exposed to within their own culture.

Institutional music education was started in colonial India by Rabindranath Tagore after he founded the Visva-Bharati University. At present, most universities have a faculty of music with some universities specially dedicated to fine arts such as Indira Kala Sangeet University, Swathi Thirunal College of Music or Rabindra Bharati University.Indian classical music is based on the gurushyshyaparampara system. The teacher, known as Guru, transmits the musical knowledge to the student, or shyshya. This is still the main system used in India to transmit musical knowledge. Although European art music became popularized in schools throughout much of the world during the twentieth century (East Asia, Latin America, Oceania, Africa), India remains one of the few highly populated nations in which non-European indigenous music traditions have consistently received relatively greater emphasis. That said, there is certainly much western influence in the popular music associated with Bollywood film scores.

In India, music education comes under the arts education with other disciplines i.e. visual arts, theater and dance in the National Curriculum Framework - 2005. It is indicated in the curriculum that music education system should be available as compulsory subject up to Class X. It is suggested that learning should be emphasized rather than teaching and the approach should be participatory, interactive and experimental.

Musical activities can lead to a sense of accomplishment, enhanced determination and persistence and of children being better able to cope with anger and express their emotions more effectively. There are also reported benefits in terms of discipline, time management, and relaxation, coping with difficulties, communication, and the ability to work with others. (Hallam, 2014).

Music is an extremely important subject for all children to learn and can lead to better brain development, increases in human connection, and even stress relief. As music is removed from schools, children will no longer receive these benefits unless they enroll in private lessons, which is much too expensive for some families to afford. They are as follows:

\section{A. MUSIC STIMULATES BRAIN DEVELOPMENT IN CHILDREN}

Various studies have found that engagement with music can lead to an improvement in brain development in children. Music education is also a great way to enhance reading comprehension abilities in children.

\section{B. MUSIC IS A WAY TO CONNECT WITH OTHER PEOPLE}

Music education is also important because it will give students a way to connect with other people. Children are naturally very social, and it's important to encourage them to build relationships by providing them experiences to share with each other. Creating a school band or small ensemble, or encouraging 
participation in a chorus will allow children to work together towards a final product (such as an end-of-year performance). This encourages bonding and will provide students with something to reminisce on together in the future.

\section{MUSIC INTEGRATES MANY DIFFERENT SUBJECTS}

Another reason music education is so important is that it integrates so many different subject areas all at once. Not only will music education allow children to develop their musical skills, it will also give them the opportunity to work on their math skills, reading and writing skills, science skills, and history knowledge.

\section{MUSIC TEACHES DISCIPLINE}

Music will also teach children to develop time management skills and discipline. If students are expected to learn their instruments and practice outside of school, then they will develop the ability to create a practice schedule and balance every other activity they have going on in their lives. Learning discipline and time management from a young age will have countless benefits on a child's future. For example, if a child develops discipline in elementary school, they will be much more able to balance the workload they'll receive in high school and excel in their classes.

\section{E. MUSIC CAN RELIEVE STRESS}

Finally, music is an excellent way to relieve stress, which is significant for students who may feel overwhelmed by schoolwork and try to balance extracurricular activities.

\section{REVIEW OF LITERATURE}

In a pilot project which investigated music attitudes and self-esteem (Nolin and Vander Ark, 1977), it was found that students with music education had significantly higher self-esteem score when measured by the Coppersmith SelfEsteem Inventory as compared to the non music students.

Annette M.B (2006) studied how background music affects the rate of language learning amongst students. The results indicated that background music has little effect on the amount of words learnt after a week. Music did not have any negative effect on language learning. It did not have any negative effect. Although the effect was found to be very little, it was found to have a positive effect.

According to Bancroff (1985), music and musical instruments can be used for therapeutic purposes rather than aesthetic ones. It is believed that music training is a very potential instrument since it finds its way into the inward places of the soul.

Hallen, Price and Katsarou (2002) suggest that calming music has a better effect on the arithmetic and memory task performance of children as compared to nonmusic condition.

Merrell and Walker (2004) assert that some sound frequencies have a positive impact on certain parts of the brain, leading to soothing effects to the students. The music that was played in the classroom brought about changes in body 
temperature, blood pressure, breathing rate and pulse rate of the students. Music made the children calmer and more obliging. Thus he believes that music can decrease the levels of anxiety and inhibition in learners. Mora states that a child can imitate the rhythm and musical contours of a language much before he can actually speak words.

Rauscher et al (1993), examined the effect of music (Mozart Sonata) on the IQ of college students. It was found that the students who were exposed to 10 minutes of Mozart Sonata scored higher on spatial-temporal reasoning tasks. In a similar study conducted by Rauscher et al (1998), Mozart music made rats complete the maze much faster and with fewer errors. This proves that classical music not only helps humans, but even rats to enhance their performance. Regina Richards proves that music, rhythm and movement provide a link between the right brain's processing of music and rhythm and the left brain's processing of verbal information.

Kirkweg (2001) conducted an experiment to study the effects of music on memory. 60 subjects were exposed to three different conditions: the Season's ie: Spring Movement by Haydn, the Holier Thou by Mettallica and the White Noise. Each group was made to study a picture for 30 seconds with the specific music in the background. It was found that in the white noise group least errors were made, while the Holier Thou group made more errors. The results obtained in this experiment contradicted a lot of research done on the effects of music and memory, for instance, it was found that the noise outside the testing area was not controlled. Besides the subjects were also talking to each other about the questionnaire while filling it up.

According to Stansell (2005), music therapists use both types of music: music to soothe or music to arouse and energize) in order to relieve different typed of psychological and physiological stressors.

\section{RESEARCH METHODOLOGY}

The objective of the study is to seek the opinion of the respondents whether music should be included as a subject in the Indian education system. Both primary and secondary sources will be dealt with. A sample of 100 housewives was selected at random for the present study. An Interview Schedule was prepared to collect the primary data.

\section{INTERPRETATION OF DATA}

Table 1 : Age of the respondents

\begin{tabular}{|c|c|c|}
\hline $\begin{array}{c}\text { Age of the respondents } \\
\text { (years) }\end{array}$ & $\begin{array}{c}\text { No. of respondents } \\
\mathbf{N = 1 0 0}\end{array}$ & $\begin{array}{c}\text { Percentage } \\
\text { (\%) }\end{array}$ \\
\hline $20-25$ & 38 & 38.00 \\
\hline $26-30$ & 35 & 35.00 \\
\hline $31-35$ & 27 & 27.00 \\
\hline Total & 100 & 100.00 \\
\hline
\end{tabular}

Source: Primary Data 
From Table 1 it is seen that 38\% of the respondents are in the age group of 20-25 years, $35 \%$ of the respondents are in $26-30$ years, and $27 \%$ of the respondents in the age group of 31-35 years respectively.

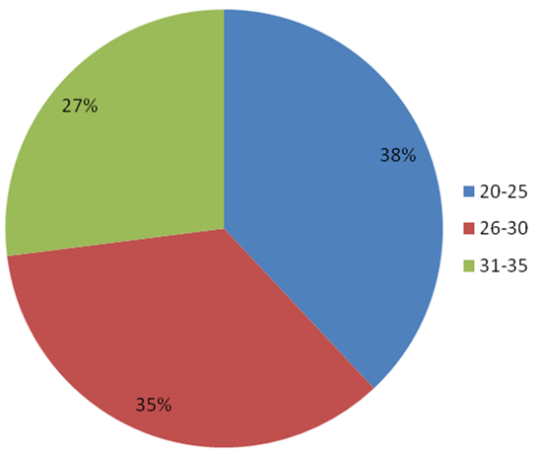

Figure 1 showing the age of the respondents

Table 2 : Educational Level of the respondents

\begin{tabular}{|c|c|c|}
\hline $\begin{array}{c}\text { Educational Level of the } \\
\text { respondents }\end{array}$ & $\begin{array}{c}\text { No. of respondents } \\
\mathbf{N = 1 0 0}\end{array}$ & $\begin{array}{c}\text { Percentage } \\
\mathbf{( \% )}\end{array}$ \\
\hline Graduate & 49 & 49.00 \\
\hline Postgraduate & 34 & 34.00 \\
\hline M.Phil/Ph.D & 17 & 17.00 \\
\hline Total & 100 & 100.00 \\
\hline
\end{tabular}

Source: Primary Data

From Table 2 it is seen that $49 \%$ of the respondents are graduate, $34 \%$ of the respondents are Postgraduates, and $17 \%$ of the respondents are M.Phil/Ph.D respectively.

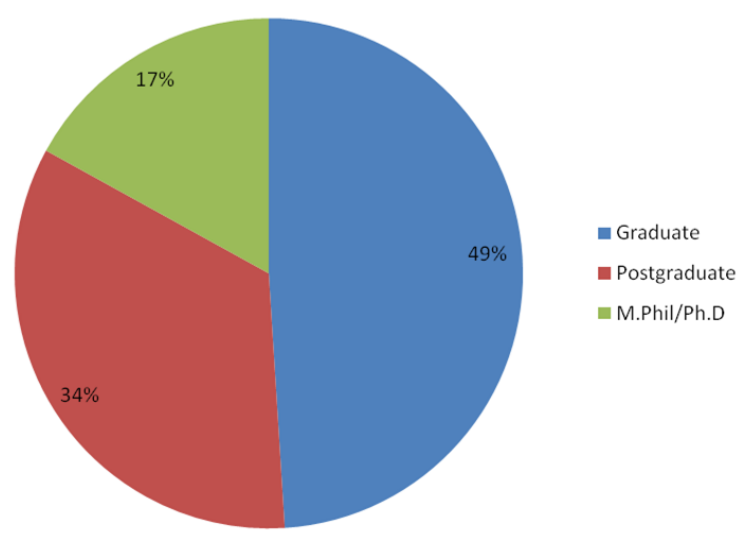

Figure 2 showing the educational level of the respondents

Table 3 : Religion of the respondents

\begin{tabular}{|c|c|c|}
\hline Religion of the respondents & $\begin{array}{c}\text { No. of respondents } \\
\mathbf{N = 1 0 0}\end{array}$ & $\begin{array}{c}\text { Percentage } \\
\text { (\%) }\end{array}$ \\
\hline Hindu & 66 & 66.00 \\
\hline Sikh & 24 & 24.00 \\
\hline Christian & 10 & 10.00 \\
\hline Total & 100 & 100.00 \\
\hline
\end{tabular}


From Table 3 it is seen that $66 \%$ of the respondents are Hindus, $24 \%$ of the respondents are Sikhs, and $10 \%$ of the respondents are Christians.

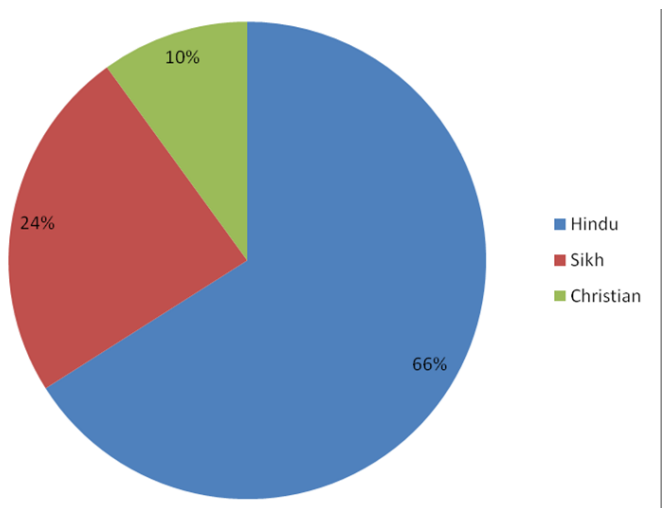

Figure 3 showing the religion of the respondents

Table 4 : Do you think there should be music class for schools?

\begin{tabular}{|c|c|c|}
\hline $\begin{array}{c}\text { Do you think there should be } \\
\text { music class for schools }\end{array}$ & $\begin{array}{c}\text { No. of respondents } \\
\mathbf{N = 1 0 0}\end{array}$ & $\begin{array}{c}\text { Percentage } \\
\text { (\%) }\end{array}$ \\
\hline Yes & 65 & 65.00 \\
\hline No & 35 & 35.00 \\
\hline Total & 100 & 100.00 \\
\hline
\end{tabular}

Source: Primary Data

From Table 4 it clearly shows that $65 \%$ of the respondents say that there should be music class in school. 35\% of the respondents that there should not be music class in school.

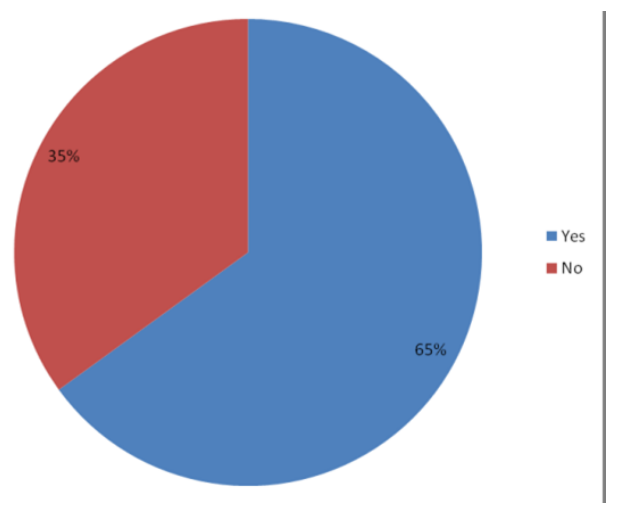

Figure 4 shows whether school should have music class

Table 5 : Do you opine that music should be introduced as a subject?

\begin{tabular}{|c|c|c|}
\hline $\begin{array}{c}\text { Do you opine that music } \\
\text { should be introduced as a } \\
\text { subject? }\end{array}$ & $\begin{array}{c}\text { No. of respondents } \\
\mathbf{N}=\mathbf{1 0 0}\end{array}$ & $\begin{array}{c}\text { Percentage } \\
\text { (\%) }\end{array}$ \\
\hline Yes & 85 & 85.00 \\
\hline No & 15 & 15.00 \\
\hline Total & 100 & 100.00 \\
\hline
\end{tabular}

Source: Primary Data 
From Table 5 it clearly shows that $85 \%$ of the respondents agree that music should be introduced as a subject in schools. $15 \%$ of the respondents do not agree that music should be introduced as a subject in schools..

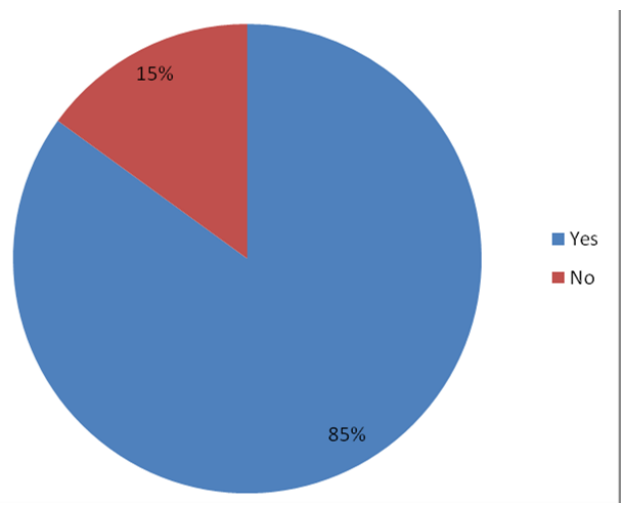

Figure 5 shows the respondents view of introducing music as a subject in school

Table 6: What is your opinion if music is introduced as a subject there should be proper infrastructure?

\begin{tabular}{|c|c|c|}
\hline $\begin{array}{c}\text { What is your opinion if music is } \\
\text { introduced as a subject there } \\
\text { should be proper infrastructure? }\end{array}$ & $\begin{array}{c}\text { No. of respondents } \\
\mathbf{N = 1 0 0}\end{array}$ & $\begin{array}{c}\text { Percentage } \\
\text { (\%) }\end{array}$ \\
\hline Yes & 90 & 90.00 \\
\hline No & 10 & 10.00 \\
\hline Total & 100 & 100.00 \\
\hline
\end{tabular}

Source: Primary Data

From Table 6 it shows that $90 \%$ of the respondents say that there should proper infrastructure in schools if music is taught as a subject whereas $10 \%$ of the respondents say there should not be any infrastructure.

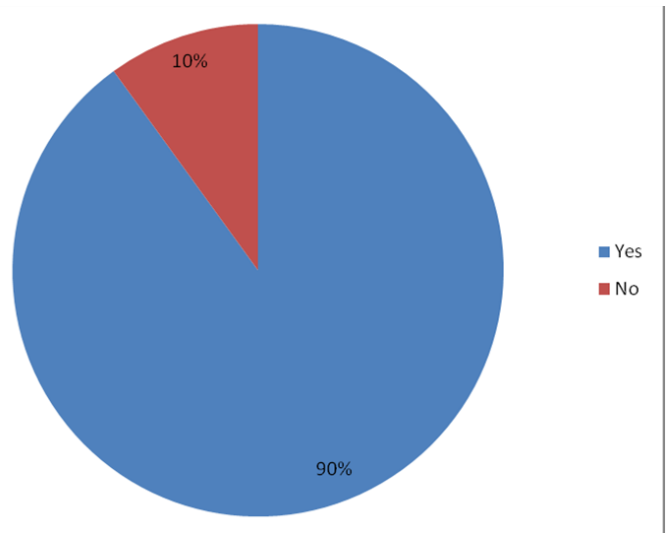

Figure 6 shows the respondents opinion of having infrastructure in schools

\section{CONCLUSION}

The Indian education system must change4d to make way for creative thinking. Music education is no doubt an important part of our lives. Music improves students' team skills and self esteem and helps their progress in other important leaning. On the other hand, it is the teacher's responsibility to deliver the best 
knowledge to the student. Teachers need to know how to stimulate their student's motivations and their best interest in music and learn other cultural teaching method as part of their study and lastly, teachers need to create more informal and social environment for student in school. Only the combination of all above will produce the best teaching result.

\section{REFERENCES}

Nolin, W. H., \& Vander Ark, S. D. (1977). A pilot study of patterns of attitudes toward school music experiences, self-esteem and socio-economic status in elementary and junior high students. Contributions to Music Education, 5, 3146.

Annette M. B. de Groot (2006) Effects of Stimulus Characteristics and Background Music on Foreign Language Vocabulary Learning and Forgetting https://onlinelibrary.wiley.com/doi/abs/10.1111/j.1467-9922.2006.00374.x Bancroft, W. J. (1985). Music therapy and education. Journal of the Society for Accelerative Learning and Teaching, 10 (1), 3-16.

Rauscher, F.H, Shaw, G.L, Ky K.N. (1993). Music and spatial task performance. Nature, 365: 611.

Hallam, S. (2014). The Power of Music: A Research Synthesis of the Impact of Actively Making Music on the Intellectual, Social and Personal Development of Children and Young People. London: International Music Education Research Centre (iMerc), University College London.

Kenneth W. Merrell and Hill M. Walker (2004). Deconstructing A Definition: Social Maladjustment Versus Emotional Disturbance And Moving The Ebd Field Forward, Psychology in the Schools, Vol. 41(8), 2004

Kirkweg, Sara B (2001). The Effects of Music on Memory. Missouri Western State College: Department of Psychology. <http://clearinghouse.missouriwestern.edu/manuscripts/230.asp>

Stansell, J. W. (2005). The use of Music for Learning Languages: A Review of the Literature. http://www.mste.uiuc.edu.

Susan Hallam, John Price \& Georgia Katsarou (2002). The Effects of Background Music on Primary School Pupils' Task Performance, Educational Studies, 28 (2):111-122. 